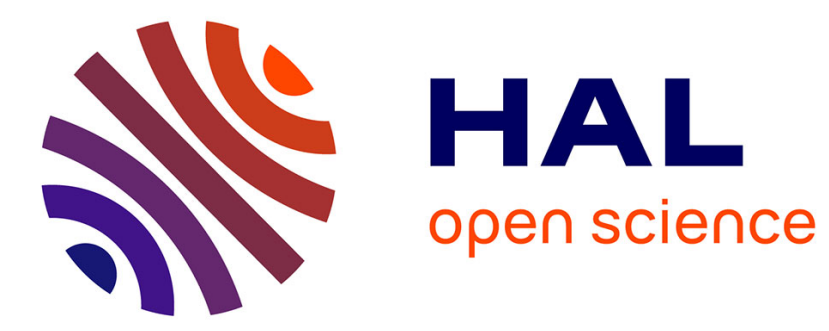

\title{
Photocatalytic Hydrogen Evolution Driven by a Heteroleptic Ruthenium(II) Bis(terpyridine) Complex
}

Mira Rupp, Thomas Auvray, Elodie Rousset, Gabriel Mercier, Valérie

Marvaud, Dirk G Kurth, Garry S Hanan

\section{- To cite this version:}

Mira Rupp, Thomas Auvray, Elodie Rousset, Gabriel Mercier, Valérie Marvaud, et al.. Photocatalytic Hydrogen Evolution Driven by a Heteroleptic Ruthenium(II) Bis(terpyridine) Complex. Inorganic Chemistry, 2019, 58 (14), pp.9127-9134. 10.1021/acs.inorgchem.9b00698 . hal-02397420

\section{HAL Id: hal-02397420 \\ https: / hal.sorbonne-universite.fr/hal-02397420}

Submitted on 6 Dec 2019

HAL is a multi-disciplinary open access archive for the deposit and dissemination of scientific research documents, whether they are published or not. The documents may come from teaching and research institutions in France or abroad, or from public or private research centers.
L'archive ouverte pluridisciplinaire HAL, est destinée au dépôt et à la diffusion de documents scientifiques de niveau recherche, publiés ou non, émanant des établissements d'enseignement et de recherche français ou étrangers, des laboratoires publics ou privés. 
Photocatalytic $\mathrm{H}_{2}$ evolution driven by a novel heteroleptic $\mathrm{Ru}(\mathrm{II})$ bis terpyridine complex

Mira Rupp ${ }^{\mathrm{a}, \mathrm{b}}$, Thomas Auvray ${ }^{\mathrm{b}}$, Elodie Rousset, ${ }^{\mathrm{b}, \mathrm{c}}$ Gabriel Mercier, ${ }^{\mathrm{b}}$ Valérie Marvaud, ${ }^{\mathrm{c}}$ Dirk G. Kurth ${ }^{\mathrm{a}^{*}}$, Garry S. Hanan ${ }^{\mathrm{b}^{*}}$

a Lehrstuhl für Chemische Technologie der Materialsynthese, Röntgenring 11, 97070 Würzburg, Germany b Département de Chimie, Université de Montréal, Montréal, H3C 3J7, Québec, Canada c Sorbonne Université, SU, CNRS UMR-8232, Institut Parisien de Chimie Moléculaire (IPCM), 4 place Jussieu, 75252 Paris Cedex 05, France

\begin{abstract}
Since the initial report by Lehn et al. in 1979, ruthenium tris(bipyridine) ([Ru(bpy) $\left.]_{3}\right]^{2+}$ ) and its numerous derivatives were applied as photosensitizers (PSs) in a large panel of photocatalytic conditions while the bis(terpyridine) analogues were disregarded because of their low quantum yields and short excited-state lifetimes. In this study, we prepared a new terpyridine ligand, 4'-(4-bromophenyl)-4,4"':4",4"''-dipyridinyl- 2,2':6',2"-terpyridine (Bipytpy) and used it to prepare the heteroleptic complex $[R u($ Tolyltpy $)(B i p y t p y)]\left(P_{6}\right)_{2}\left(\mathbf{1} ;\right.$ Tolyltpy $=4^{\prime}-$ tolyl-2,2':6',2'-terpyridine). Complex 1 exhibits enhanced photophysical properties with a higher quantum yield $\left(7.4 \times 10^{-4}\right)$ and a longer excited-state lifetime (3.8 ns) compared to those of $\left[\mathrm{Ru}(\text { Tolyltpy })_{2}\right]\left(\mathrm{PF}_{6}\right)_{2}\left(3 \times 10^{-5}\right.$ and $0.74 \mathrm{~ns}$, respectively). These enhanced photophysical characteristics and the potential for PS-catalyst interaction through the peripheral pyridines led us to apply the complex for visible-light-driven hydrogen evolution. The photocatalytic system based on 1 as the PS, triethanolamine as a sacrificial donor, and cobaloxime as a catalyst exhibits sustained activity over more than 10 days under blue-light irradiation (light-emitting diode centered at $450 \mathrm{~nm}$ ). A maximum turnover number of 764 was obtained after 12 days.
\end{abstract}

\title{
Introduction
}

Ruthenium tris bipyridine complexes have become the archetypical model compound for transition metal ion-based photosensitizers in photocatalytic reactions. ${ }^{1,2}$ For the ability to function as a photosensitizer, a long excited-state lifetime and a high quantum yield are necessary in order to efficiently transfer electrons to the catalyst. ${ }^{3}$ Ruthenium tris bipyridine 
complexes offer these properties, associated with a high degree of tunability allowing one to adjust the complex's redox potentials and push the absorption to cover the entire visible spectrum. Numerous studies using ruthenium, as well as iridium or rhenium photosensitizers showed that the presence of interactions between the photosensitizer and the catalyst leads to an enhancement of the overall photocatalytic activity. ${ }^{4-7}$ Recently, Mulfort and Tiede suggested that a photosensitizer capable of coordinating to the catalytic center could overcome diffusional constraints and enable efficient intermolecular electron transfer. Even though they did not observe activity in hydrogen production for their systems, their investigations and results confirm this to be a promising approach. ${ }^{8}$ Interestingly, they considered the use of a ruthenium bis terpyridine complex as photosensitizer and showed that through suitable design of a donor-acceptor system, efficient electron transfer could be observed. This is surprising as ruthenium bis terpyridine complexes have been disregarded as photosensitizer due to their low quantum yield and short excited-state lifetime resulting from the low lying non-radiative metal center excited state, which is easily populated at room temperature. ${ }^{9-11}$ However, the linear $\mathrm{D}_{2 \mathrm{~d}}$ symmetry of bis-tridentate complexes, which comes without stereoisomers compared to the three-fold $\mathrm{D}_{3}$ symmetry of tris bidentate complexes, offers a suitable connectivity for directional electron transfer. In addition, the coordination geometry of the bis terpyridine complex allows the design of linear arrays or polymers, ${ }^{12-14}$ whose properties can be tuned by using different spacers as well as substituents. ${ }^{15-17}$ Despite intensive efforts dedicated to improving their photophysical properties, ruthenium bis tridentate complexes have, to the best of our knowledge, not been shown to photocatalyze hydrogen production. ${ }^{18,19}$ Herein, we report a newly designed heteroleptic complex capable of coordinating to the catalyst via peripheral pyridine substituents and discuss its photophysical and electrochemical properties as well as its potential as photosensitizer in hydrogen production experiments.

\section{Experimental}

Material. The ligand Tolyltpy was prepared according to published procedure. ${ }^{20}$ The synthesis of the precursor 2-acetyl-4,4'-bipyridine was optimized in our laboratory from previous work. ${ }^{21,22}$ The complexation was carried out as a two-step procedure adapted from the literature. ${ }^{23}$ All reagents and solvents were obtained from commercial sources (VWR, Fisher Scientific, Acros or Sigma Aldrich) and used as received, unless stated otherwise. $\mathrm{RuCl}_{3} \cdot 3 \mathrm{H}_{2} \mathrm{O}$ was obtained from Pressure Chemicals. 
Synthesis. 2-acetyl-4,4'-bipyridine: A solution of 4,4'-bipyridine (3.00 g, $19.2 \mathrm{mmol}, 1 \mathrm{eq})$, iron(II) sulfate heptahydrate $(267 \mathrm{mg}, 960 \mu \mathrm{mol}, 0.05 \mathrm{eq})$, acetaldehyde $(5.40 \mathrm{~mL}, 4.23 \mathrm{~g}$, $96.0 \mathrm{mmol}, 5 \mathrm{eq})$, tert-butylhydroperoxide $(26.6 \mathrm{~mL}, 17.3 \mathrm{~g}, 192 \mathrm{mmol}, 10 \mathrm{eq})$ and trifluoroacetic acid $(7.40 \mathrm{~mL}, 11.0 \mathrm{~g}, 96.0 \mathrm{mmol}, 5 \mathrm{eq})$ in acetonitrile $(60 \mathrm{~mL})$ was heated to reflux for 90 minutes. Subsequently, the acetonitrile was removed under reduced pressure and the $\mathrm{pH}$ of the residue was raised to approximately 9 by adding $1 \mathrm{M}$ aqueous sodium carbonate. After extraction with dichloromethane, the organic phase was dried over magnesium sulfate and the solvent removed under reduced pressure. The crude product was purified by column chromatography (silica gel, ethyl acetate) to yield the pure product as an off-white solid (1.60 g, $8.07 \mathrm{mmol}, 42 \%) .{ }^{1} \mathrm{H}-\mathrm{NMR}\left(400 \mathrm{MHz}, \mathrm{CDCl}_{3}\right): \delta=8.81(\mathrm{~d}, 1 \mathrm{H}$, $\left.{ }^{3} J=5.1 \mathrm{~Hz}, \mathrm{Py} H^{6}\right), 8.77\left(\mathrm{dd}, 2 \mathrm{H},{ }^{3} J=4.4 \mathrm{~Hz},{ }^{4} J=1.6 \mathrm{~Hz}, \mathrm{Py}{ }^{2} H^{2,6}\right), 8.31\left(\mathrm{~d}, 1 \mathrm{H},{ }^{4} J=1.2 \mathrm{~Hz}\right.$, Py $\left.H^{3}\right), 7.72\left(\mathrm{dd}, 1 \mathrm{H},{ }^{3} J=5.1 \mathrm{~Hz},{ }^{4} J=1.9 \mathrm{~Hz}, \mathrm{Py} H^{5}\right), 7.59\left(\mathrm{dd}, 2 \mathrm{H},{ }^{3} J=4.5 \mathrm{~Hz},{ }^{4} J=1.7 \mathrm{~Hz}\right.$, Py' $\left.H^{3,5}\right)$ and $2.78\left(\mathrm{~s}, 3 \mathrm{H}, \mathrm{CO}\left(\mathrm{CH}_{3}\right)\right) .{ }^{13} \mathrm{C}-\mathrm{NMR}\left(101 \mathrm{MHz}, \mathrm{CDCl}_{3}\right): \delta=26.0,119.4,121.5$, 124.6, 144.9, 146.7, 150.1, 150.9, 154.5, 199.9. Elemental analysis calcd (\%) for $\mathrm{C}_{12} \mathrm{H}_{10} \mathrm{~N}_{2} \mathrm{O}$ : C 72.71, H 5.08, N 14.13; found: C 72.43, H5.11, N 13.67. HRMS (ESI-TOF) m/z: [M+Na] ${ }^{+}$ Calcd for $\mathrm{C}_{12} \mathrm{H}_{10} \mathrm{~N}_{2} \mathrm{NaO} 221.0685$; found 221.0685 .


of 2-acetyl-4,4'-bipyridine (500 mg, $2.52 \mathrm{mmol}, 2.5 \mathrm{eq})$ in ethanol (25 mL), 4bromobenzaldehyde (187 mg, $1.01 \mathrm{mmol}, 1 \mathrm{eq})$, potassium hydroxide (283 mg, $5.04 \mathrm{mmol}$, $5 \mathrm{eq})$ and aqueous ammonia (28 weight\%, $7.02 \mathrm{~mL}, 6.32 \mathrm{~g}, 50.4 \mathrm{mmol}, 50 \mathrm{eq})$ were added. The reaction mixture was heated to reflux for two weeks. Subsequently, water was added to precipitate the product, which was filtered over celite, washed with water and methanol and dissolved in dichloromethane. The solution was dried over magnesium sulfate and the solvent was removed under reduced pressure. The crude product was suspended in methanol and the slurry filtered to give the product as a white solid $(251 \mathrm{mg}, 463 \mu \mathrm{mol}, 46 \%)$. ${ }^{1} \mathrm{H}-\mathrm{NMR}$ $\left(300 \mathrm{MHz}, \mathrm{CDCl}_{3}\right): \delta=8.89\left(\mathrm{~d}, 2 \mathrm{H},{ }^{4} J=1.8 \mathrm{~Hz}, \mathrm{Py} H^{3} / \mathrm{Py}^{\mathrm{c}} H^{3}\right), 8.86\left(\mathrm{dd}, 2 \mathrm{H},{ }^{3} J=5.1 \mathrm{~Hz}\right.$, ${ }^{4} J=0.7 \mathrm{~Hz}, \mathrm{Py} H^{6} / \mathrm{Py}{ }^{\prime} H^{6}$ ), $8.80\left(\mathrm{dd}, 4 \mathrm{H},{ }^{3} J=4.5 \mathrm{~Hz},{ }^{4} J=1.7 \mathrm{~Hz}, \mathrm{Py}{ }^{\prime}{ }^{\prime} H^{2,6} / \mathrm{Py}{ }^{\prime,},{ }^{2,6}\right), 8.79$ (s, 2H, Py' $\left.H^{3,5}\right), 7.81\left(\mathrm{dd},{ }^{3} J=6.6 \mathrm{~Hz},{ }^{4} J=2.0 \mathrm{~Hz}, 2 \mathrm{H}, \mathrm{Ph} H\right), 7.68(\mathrm{~m}, 6 \mathrm{H}, \mathrm{Ph} H /$ Py" ', $\left.H^{3,5} / \mathrm{Py},{ }^{\prime \prime}, H^{3,5}\right)$ and $7.62 \mathrm{ppm}\left(\mathrm{dd},{ }^{3} J=5.1 \mathrm{~Hz},{ }^{4} J=1.8 \mathrm{~Hz}, 2 \mathrm{H}, \mathrm{Py} H^{5} / \mathrm{Py}{ }^{\prime \prime} H^{5}\right) .{ }^{13} \mathrm{C}\left\{{ }^{1} \mathrm{H}\right\}-$ $\operatorname{NMR}\left(101 \mathrm{MHz}, \mathrm{CDCl}_{3}\right): \delta=157.1,156.0,150.9,150.3,149.6,146.8,146.1,137.3,132.4$, $129.0,123.9,121.8,121.7,119.5$ and $119.3 \mathrm{ppm}$. ESI-MS: $\mathrm{m} / \mathrm{z}[\mathrm{M}+\mathrm{H}]^{+}$cacld for $\mathrm{C}_{31} \mathrm{H}_{20} \mathrm{BrN}_{5}$ : 542.0975; found: 542.0887; difference: $16.2 \mathrm{ppm}$

[Ru(Tolytpy)Cl 3$]$ : A solution of ruthenium(III) chloride trihydrate (261 mg, $1.00 \mathrm{mmol}, 1 \mathrm{eq})$ and Tolyltpy (323 mg, $1.00 \mathrm{mmol}, 1 \mathrm{eq})$ in ethanol $(125 \mathrm{~mL})$ was heated to reflux for 3 hours. 
Subsequently, the reaction mixture was filtered and the residue washed with ethanol to yield a red-brown solid (470 $\mathrm{mg}, 885 \mu \mathrm{mol}, 89 \%)$. The product was used without further purification.

[Ru(Tolyltpy)(Bipytpy)](PF $)_{2}$ : A suspension of $\left[\mathrm{RuCl}_{3}\right.$ (Tolyltpy)] (75.0 mg, $\left.141 \mu \mathrm{mol}, 1 \mathrm{eq}\right)$, Bipytpy (76.6 mg, $141 \mu \mathrm{mol}, 1 \mathrm{eq})$ and four drops of trimethylamine in $15.0 \mathrm{~mL}$ ethylene glycol was heated to $170{ }^{\circ} \mathrm{C}$ for 25 minutes using microwave irradiation. After cooling to room temperature water and aqueous $\mathrm{KPF}_{6}$ solution were added to the solution and the precipitate filtered off over celite. After washing with water, it was dissolved in acetonitrile, dried over magnesium sulfate and the solvent was removed under reduced pressure. Traces of ethylene glycol were removed by washing the crude product with water. It was further purified by column chromatography (silica gel, $\mathrm{MeCN}$ : $\mathrm{KNO}_{3(\mathrm{aq})} 7: 1$ ) to yield a dark red solid (138 mg, $110 \mu \mathrm{mol}, 78 \%$ \%). ${ }^{1} \mathrm{H}-\mathrm{NMR}\left(400 \mathrm{MHz}, \mathrm{CD}_{3} \mathrm{CN}\right): \delta=9.22$ (s, 2H), 9.06 (s, 2H), 8.99 $\left(\mathrm{d},{ }^{4} J=1.6 \mathrm{~Hz}, 2 \mathrm{H}\right), 8.79\left(\mathrm{dd},{ }^{3} J=4.5 \mathrm{~Hz},{ }^{4} J=1.6 \mathrm{~Hz}, 4 \mathrm{H}\right), 8.70\left(\mathrm{~d},{ }^{3} J=8.1 \mathrm{~Hz}, 2 \mathrm{H}\right), 8.25(\mathrm{~d}$, $\left.{ }^{3} J=8.6 \mathrm{~Hz}, 2 \mathrm{H}\right), 8.16\left(\mathrm{~d},{ }^{3} J=8.2 \mathrm{~Hz}, 2 \mathrm{H}\right), 7.99(\mathrm{~m}, 4 \mathrm{H}), 7.76\left(\mathrm{dd},{ }^{3} J=4.5 \mathrm{~Hz},{ }^{4} J=1.7 \mathrm{~Hz}\right.$ $4 \mathrm{H}), 7.63\left(\mathrm{~d},{ }^{3} J=7.9 \mathrm{~Hz}, 2 \mathrm{H}\right), 7.60\left(\mathrm{~d},{ }^{3} J=5.9 \mathrm{~Hz}, 2 \mathrm{H}\right), 7.54\left(\mathrm{dd},{ }^{3} J=5.9 \mathrm{~Hz},{ }^{4} J=2.0 \mathrm{~Hz}\right.$, $2 \mathrm{H}), 7.48\left(\mathrm{~d},{ }^{3} J=4.9 \mathrm{~Hz}, 2 \mathrm{H}\right), 7.23\left(\mathrm{ddd},{ }^{3} J=7.1 \mathrm{~Hz},{ }^{3} J=5.6 \mathrm{~Hz},{ }^{4} J=1.2 \mathrm{~Hz}, 2 \mathrm{H}\right)$ and $2.55 \mathrm{ppm}(\mathrm{s}, 3 \mathrm{H}) .{ }^{13} \mathrm{C}\left\{{ }^{1} \mathrm{H}\right\}-\mathrm{NMR}\left(75 \mathrm{MHz}, \mathrm{CD}_{3} \mathrm{CN}\right): \delta=159.9,159.2,156.6,156.3,155.6$, $153.8,153.5,151.8,149.8,148.2$, 148.0, 143.7, 142.1, 139.2, 136.9, 133.8, 131.3, 130.6, $128.7,128.5,125.9,125.5,123.4,123.3,122.9,122.5,122.5$ and 21.4 ppm. ESI-MS: m/z [M - $\left.\mathrm{PF}_{6}\right]^{+}$cacld for $\mathrm{C}_{53} \mathrm{H}_{37} \mathrm{BrF}_{6} \mathrm{~N}_{8} \mathrm{PRu}$ : 1111.10044; found: 1111.09792; difference: $3.1 \mathrm{ppm}$. Anal. cacld for $\mathrm{C}_{53} \mathrm{H}_{37} \mathrm{BrF}_{12} \mathrm{~N}_{8} \mathrm{P}_{2} \mathrm{Ru}, 2 \mathrm{H}_{2} \mathrm{O}$ : C, 49.24; H, 3.20; N, 8.67. Found: C, 48.84; H, $3.06 ; \mathrm{N}, 8.36$.

\section{Results and discussion}

Synthesis and structural characterizations. The synthesis of the ligand $4^{6}-(p-$ bromophenyl)-4,4" ':4“",4",' -di-pyridinyl-2,2‘:6“,2“"-terpyridine (Bipytpy) is carried out using 2-acetyl-4,4'-bipyridine analogously to a one-pot reaction described previously. ${ }^{20}$ The synthesis of this monoacetylated precursor was previously mentioned as traces in the acetylation of 4,4'-bipyridine. ${ }^{21}$ The careful investigation leading to the new protocol used here, allowed us to reduce the amount of poly-acetylated products and isolate the desired compound in good yield and purity. ${ }^{21,22}$ The heteroleptic complex is prepared via a two-step synthesis, adapted from Fallahpour et al. ${ }^{23}$ First, a $\mathrm{Ru}(\mathrm{III})$ complex is formed by the reaction of hydrated $\mathrm{RuCl}_{3}$ with $p$-tolyl-2,2‘:6‘,2“"-terpyridine (Tolyltpy). This complex is reacted with 
Bipytpy under microwave conditions to yield the heteroleptic Ru(II) complex in $78 \%$ yield (

2<smiles>CC(=O)c1cc(-c2ccncc2)ccn1</smiles>

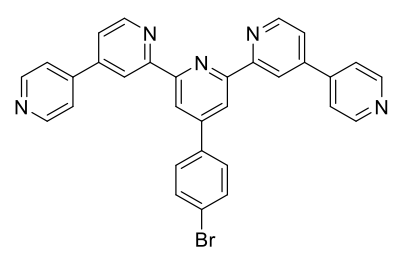

1. $\left[\mathrm{Ru}(\right.$ Tolyltpy $\left.) \mathrm{Cl}_{3}\right]$ $\mathrm{NEt}_{3}$, ethylene glycol $\underset{\mathrm{MW}}{\stackrel{2}{ }\left(170^{\circ} \mathrm{C}, 25 \mathrm{~min}\right)}$

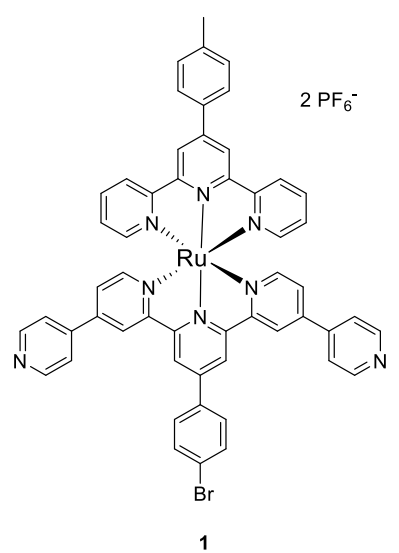

Scheme 1). Both the ligand and the complex are characterized by ${ }^{1} \mathrm{H}$ and ${ }^{13} \mathrm{C}$ NMR spectroscopy as well as high-resolution mass spectrometry.

2<smiles>CC(=O)c1cc(-c2ccncc2)ccn1</smiles>



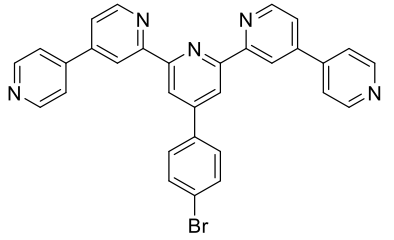
1. $\left[\mathrm{Ru}\right.$ (Tolyltpy) $\left.\mathrm{Cl}_{3}\right]$ $\mathrm{NEt}_{3}$, ethylene glycol $\mathrm{MW}\left(170^{\circ} \mathrm{C}, 25 \mathrm{~min}\right)$

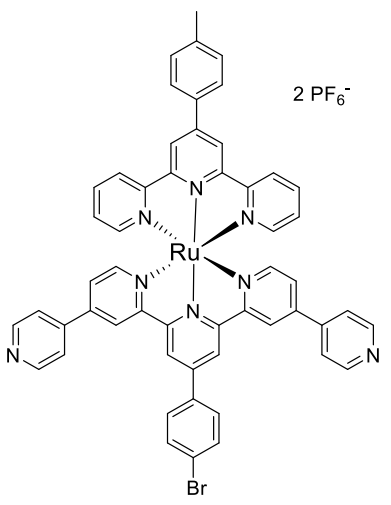

Scheme 1. Synthetic pathway towards complex $1\left[\mathrm{Ru}(\right.$ Tolyltpy)(Bipytpy) $]\left(\mathrm{PF}_{6}\right)_{2}$. 
X-Ray analysis was performed on a single-crystal of the complex $\left[\mathrm{Ru}(\right.$ Tolyltpy)(Bipytpy) $]\left(\mathrm{PF}_{6}\right)_{2} \mathbf{1}$ obtained by slow diffusion of diethyl ether in a concentrated acetonitrile solution of the complex (Figure 1). The central ruthenium ion is embedded in a distorted octahedral coordination sphere, imposed by the restricted bite angle of the two meridionally coordinated terpyridine ligands. The Tolyltpy is slightly bent due to intramolecular interactions, i.e. weak stacking between the terminal tolyl group and one of the lateral pyridines of the Tolyltpy of a neighboring complex and $\mathrm{H}$ bonding involving the pendant pyridines (see Figure S2-S3). A similar bending induced by interaction in the crystal packing was recently reported by Beves et al. in their work of crystal engineering using

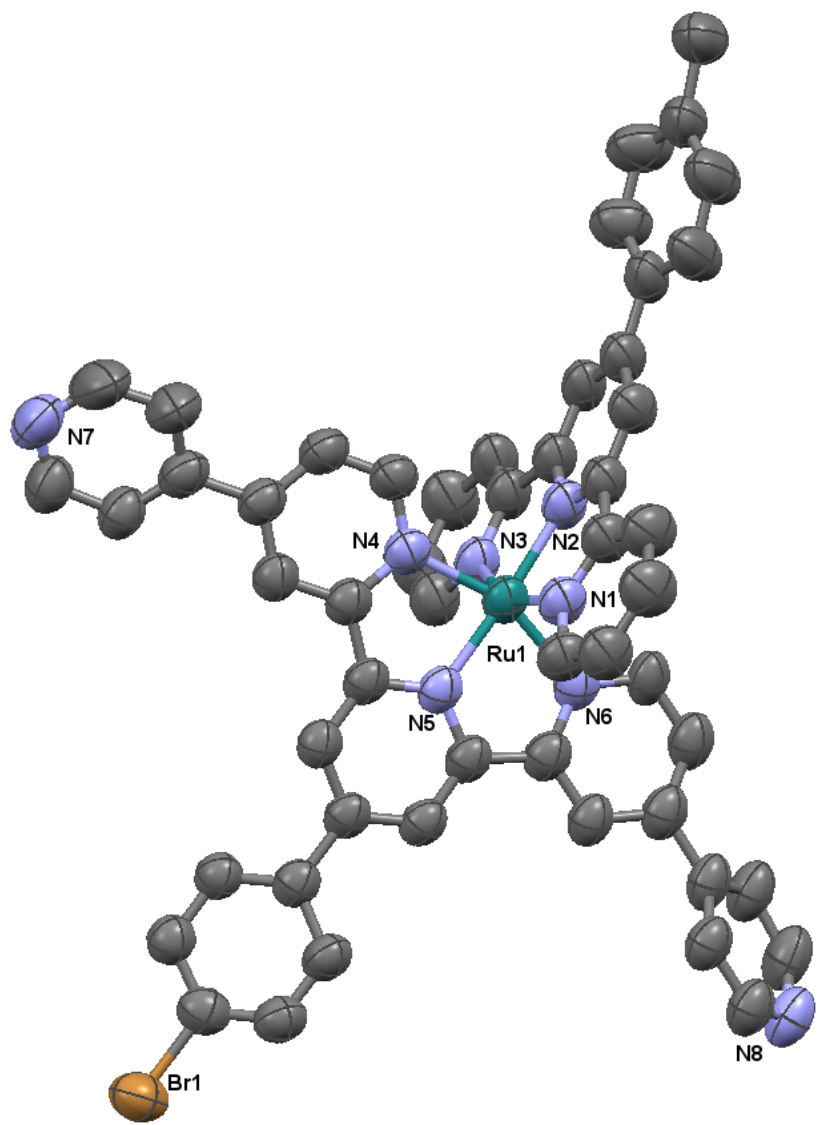

heteroleptic ruthenium bis terpyridine complexes as building blocks. ${ }^{24}$ Finally, the structure shows that the pendant pyridines are not fully coplanar with the terpyridine unit, with torsion angles around 23 and 45 degrees, as observed in other polypyridine based systems. ${ }^{6}$ 
Figure 1. Ellipsoid representation of $\left[\mathrm{Ru}(\text { Tolyltpy)(Bipytpy) }]^{2+} \mathbf{1}\right.$ at $50 \%$ probability. Hydrogen atoms, $\mathrm{PF}_{6}^{-}$counter ions and co-crystallized solvent molecules are omitted for clarity.

Electronic properties. The non-symmetric design of complex 1 involves two terpyridines ligands with different electron densities in order to facilitate the transfer of electron density towards the Bipytpy ligand in the excited state, thus favoring directional electron transfer. The success of our design is confirmed by the electrochemical experiments conducted in acetonitrile, whose results are summarized in Table 1. The cyclic voltammogram of complex 1 (see Figure S1) shows one reversible oxidation and three reversible reduction processes. The oxidation process at $+1.21 \mathrm{~V}$ vs SCE corresponds to the $\mathrm{Ru}(\mathrm{II})$ to $\mathrm{Ru}(\mathrm{III})$ oxidation. To assign the three reduction waves, we compare them to that of the homoleptic complex $\left.[\mathrm{Ru} \text { (Tolyltpy })_{2}\right]^{2+}$. The first reduction of the heteroleptic complex is at a slightly lower negative potential than for the homoleptic complex and corresponds thus to the reduction of the Bipytpy ligand. Bipytpy is easier to reduce due to its electron withdrawing substituents and the extended conjugated $\pi$-system. The second reduction process takes place at the Tolyltpy ligand and the observed potential is in agreement with the one observed for the homoleptic species. The third reduction corresponds to a second reduction of the Bipytpy ligand. The experimentally determined redox processes and their assignments are confirmed by the theoretical calculations performed on complex $\mathbf{1}$ (details on the parameters used are available in the SI). Selected molecular orbitals of complex 1 are presented in Table 2 (additional orbitals along with their respective molecular contributions are presented in Table $\mathrm{S} 1)$.

Table 1. Electrochemical half-wave redox potentials of complex 1 [Ru(Tolyltpy)(Bipytpy) $]^{+2}$ compared to $\left[\mathrm{Ru}(\text { Tolyltpy })_{2}\right]^{2+}$ in acetonitrile. ${ }^{\mathrm{a}}$

\begin{tabular}{|c|c|c|c|c|}
\hline & $E_{1 / 2}^{O x}$ & $E_{1 / 2}^{R e d 1}$ & $E_{1 / 2}^{R e d 2}$ & $E_{1 / 2}^{R e d 3}$ \\
\hline$\left[R u(\text { Tolyltpy)(Bipytpy)] }]^{+2}\right.$ & $+1.21(85)$ & $-1.17(75)$ & $-1.46(71)$ & $-1.66(86)$ \\
\hline$[\text { Ru(Tolyltpy) }]^{+2}$ & $+1.22(69)$ & $-1.24(42)$ & $-1.48(67)$ & \\
\hline
\end{tabular}


The impact of our design on the absorption spectra of the complex is analyzed using UV-vis absorption spectroscopy. The spectrum is shown in Figure 2 and the major bands are summarized in Table, where they are compared to the homoleptic Tolyltpy complex. The transition at $\lambda=497 \mathrm{~nm}$ is slightly red-shifted compared to the homoleptic complex; this transition is known to correspond to metal-to-ligand charge transfers (MLCT), as confirmed by TD-DFT. The other major bands visible in the spectrum (see Figure 2) correspond to ligand-centered (LC) transitions.

Table 2. Representation of the molecular orbitals of interest (isocontour value 0.03 a.u.).

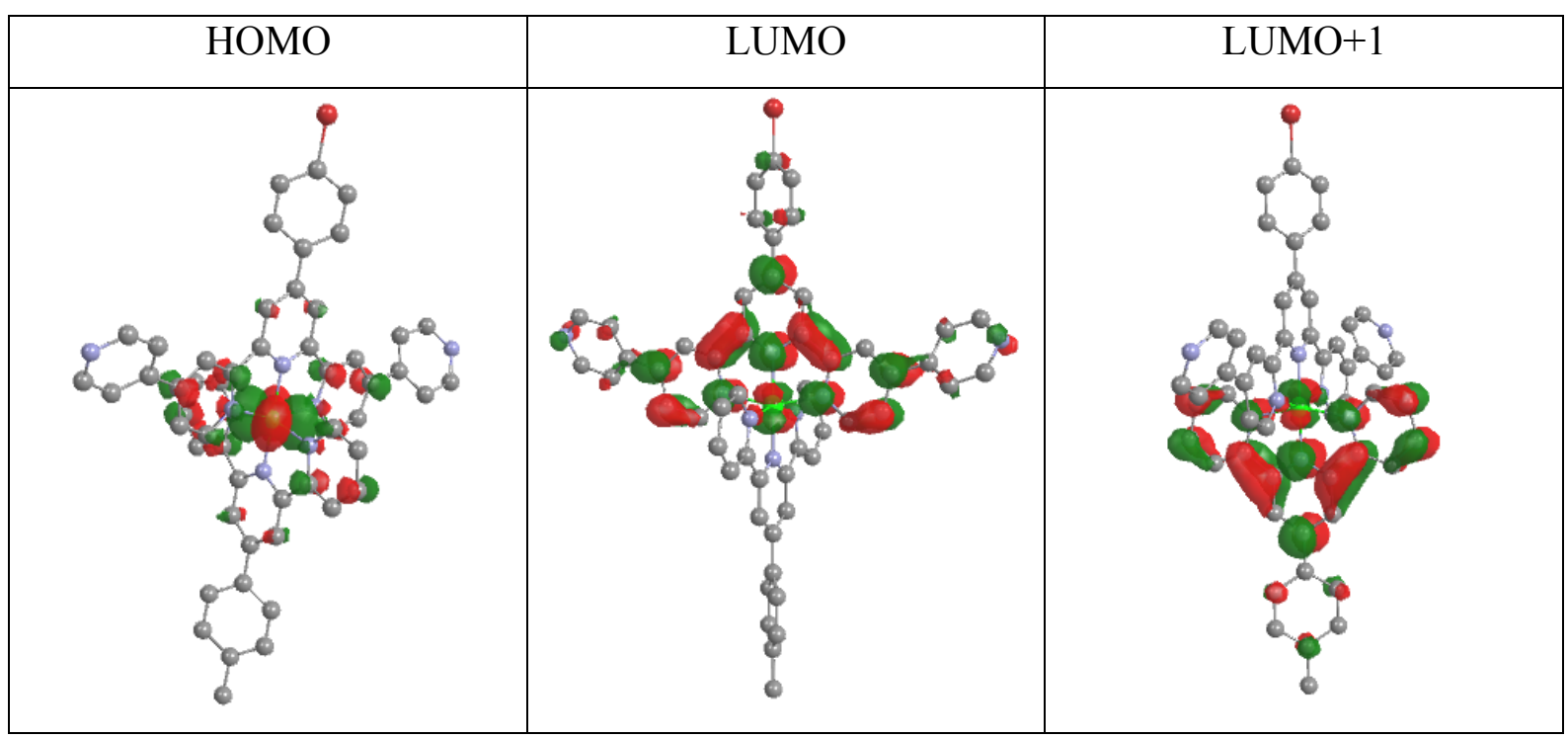




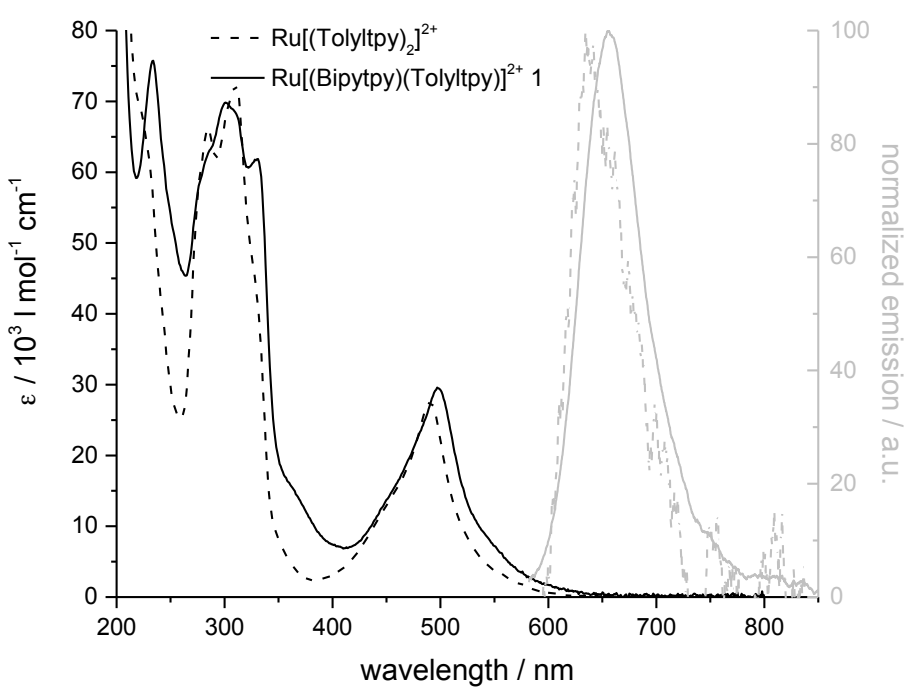

Figure 2. UV-vis absorption (black) and normalized room-temperature emission spectra (grey) of complex $1\left[\operatorname{Ru}(\text { Tolyltpy)(Bipytpy) }]^{2+}\right.$ (solid line) and reference $\left[\operatorname{Ru}(\text { Tolyltpy) })^{2+}\right.$ (dashed line) measured in acetonitrile.

Table 3. UV-vis absorption and emission data of complex $1\left[\operatorname{Ru}(\text { Tolyltpy)(Bipytpy) }]^{2+}\right.$ compared to $\left[\mathrm{Ru}(\text { Tolyltpy })_{2}\right]^{2+}$; spectra measured in acetonitrile.

\begin{tabular}{|c|c|c|c|c|c|c|c|}
\hline & \multicolumn{4}{|c|}{$\lambda_{\max \text { abs. }} / \mathrm{nm}\left(\varepsilon / 10^{3} \mathrm{~L} \cdot \mathrm{mol}^{-1} \cdot \mathrm{cm}^{-1}\right)$} & \multirow{2}{*}{$\begin{array}{l}\lambda_{\text {max em. }} / \\
\mathrm{nm}\end{array}$} & \multirow{2}{*}{$\begin{array}{l}\Phi_{c} / \\
10^{-5}\end{array}$} & \multirow[t]{2}{*}{$\tau_{c} / \mathrm{ns}$} \\
\hline & & $\mathrm{LC}$ & & MLCT & & & \\
\hline$[\text { Ru(Tolyltpy)(Bipytpy) }]^{2+}$ & $\begin{array}{l}233 \\
(93)\end{array}$ & $\begin{array}{l}302 \\
(80)\end{array}$ & $\begin{array}{l}330 \\
(71)\end{array}$ & $\begin{array}{l}497 \\
(34)\end{array}$ & 656 & $74 \pm 33$ & $3.8 \pm 0.1$ \\
\hline$\left[\operatorname{Ru}(\text { Tolyltpy })_{2}\right]^{2+}$ & $\begin{array}{l}285 \\
(58)\end{array}$ & $\begin{array}{l}310 \\
(64)\end{array}$ & & $\begin{array}{l}491 \\
(23)\end{array}$ & 636 & $3 \pm 1^{\mathrm{b}}$ & $\begin{array}{c}0.74 \pm \\
0.02^{\mathrm{b}}\end{array}$ \\
\hline${ }^{\mathrm{b}}$ from ref. 24 & & & & & & & \\
\hline
\end{tabular}

Room-temperature fluorescence is recorded in argon purged acetonitrile solutions. The quantum yield is determined using the optically dilute measurement method $^{25}$ with $\left.[\mathrm{Ru} \text { (Tolyltpy })_{2}\right]^{+2}$ as reference. ${ }^{26}$ The data is summarized in Table 3. The maximum of the emission wavelength is slightly red shifted to $656 \mathrm{~nm}$ in comparison to the homoleptic Tolyltpy complex at $636 \mathrm{~nm}$. As expected, the quantum yield $\Phi_{c}$ and excited-state lifetime are significantly lower than for $\mathrm{Ru}(\mathrm{II})$ tris bidentate complexes. ${ }^{5}$ When comparing complex $\mathbf{1}$ with other $\mathrm{Ru}(\mathrm{II})$ terpyridine complexes, however, the quantum yield is increased by an order 
of magnitude while the excited-state lifetime of the heteroleptic complex is increased to $3.8 \mathrm{~ns}^{26}$ This excited-state lifetime can allow reductive or oxidative quenching to take place more efficiently in the context of a photocatalytic experiment. In this regard, the redox potentials for the excited photosensitizer are estimated using the following equations: $\mathrm{E}^{*}{ }_{\mathrm{ox}}=$ $\mathrm{E}_{\mathrm{ox}}-\mathrm{E}_{\mathrm{em}}$ and $\mathrm{E}_{\text {red }}^{*}=\mathrm{E}_{\mathrm{red}}+\mathrm{E}_{\mathrm{em}}$, where $\mathrm{E}_{\mathrm{em}}(\mathrm{eV}) \approx 1240 / \lambda_{\mathrm{em}}(\mathrm{nm})$, giving potentials of $-0.66 \mathrm{~V}$ and $0.71 \mathrm{~V} v s \mathrm{SCE}$ for the oxidation and reduction respectively of the excited photosensitizer.

Spectroelectrochemical measurements of complex $\mathbf{1}$ were conducted. The change in absorption during oxidation of the complex is shown in Erreur! Source du renvoi introuvable. The most significant change is the decrease of the MLCT absorption band. Instead, an increasing absorption band at round $400 \mathrm{~nm}$ is observed. It can be assigned to a ligand-to-metal charge transfer (LMCT) transition, possible due to the oxidation of the metalcentered HOMO.



Figure 3. UV-vis absorption spectra of $\left[\operatorname{Ru}(\text { Tolyltpy)(Bipytpy) }]^{2+} 1\right.$ in argon purged acetonitrile at different oxidation potentials from $0.0 \mathrm{~V}$ to $1.5 \mathrm{~V} v s \mathrm{Ag} / \mathrm{Ag}^{+}$.

The change in absorption during the reduction of the complex is shown in Erreur ! Source du renvoi introuvable. The intensity of the MLCT band hardly changes indicating that this transition is not affected by the reduction of the complex. The electrochemically reversible reduction processes observed in cyclic voltammetry already led to the assumption that the reduction processes are ligand centered, resulting in a stable $\mathrm{d}^{6}$ complex. The spectroelectrochemical experiments confirm this conclusion. 
The broadening of the peak around $490 \mathrm{~nm}$ could be assigned to a ligand-to-metal charge transfer (LMCT) transition due to the population of the non-bonding orbital, which can be excited to an anti-bonding metal-centered orbital.

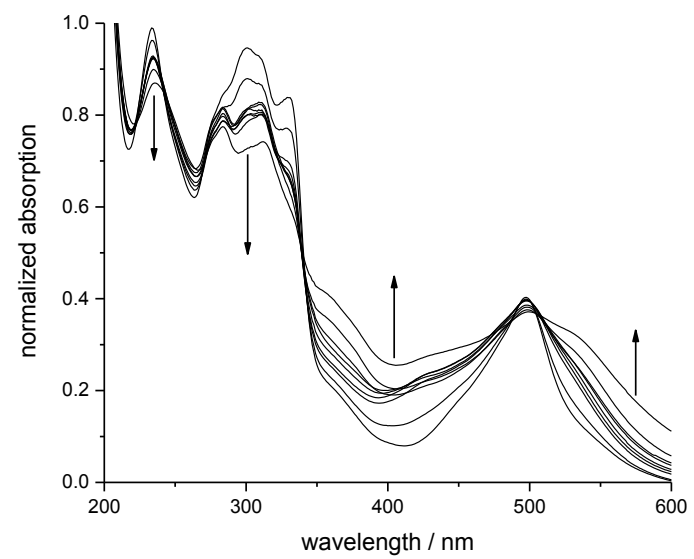

Figure 4. UV-vis absorption spectra of $\left[\operatorname{Ru}(\text { Tolyltpy)(Bipytpy) }]^{2+} \mathbf{1}\right.$ in argon purged acetonitrile at different reduction potentials from $0.0 \mathrm{~V}$ to $-2.0 \mathrm{~V} v s \mathrm{Ag} / \mathrm{Ag}^{+}$.

Photocatalytic experiments. Based on the enhanced excited-state lifetime and quantum yield, the potential of complex $\mathbf{1}$ to act as photosensitizer in hydrogen evolution was investigated. Two types of catalysts were used, either $\mathrm{K}_{2}\left[\mathrm{PtCl}_{4}\right]$ as precursor for platinum colloids as heterogeneous active species or cobaloxime such as $\left[\mathrm{Co}(\mathrm{dmgH})\left(\mathrm{dmgH}_{2}\right) \mathrm{Cl}_{2}\right]$ ( $\mathrm{dmgH}_{2}$ : dimethyl glyoxime) as homogeneous catalyst (experimental details are given in the SI). These catalysts are known from previous investigations to show high activity in hydrogen production experiments. ${ }^{27,}{ }^{28}$ Erreur ! Source du renvoi introuvable. shows the turn-over frequency (TOF) of the first $24 \mathrm{~h}$ of hydrogen evolution experiments with $[\mathrm{Ru} \text { (Tolyltpy)(Bipytpy) }]^{2+}$ and different catalysts. In the absence of one of the components or light, no hydrogen evolution is detected. Under irradiation, both the homogeneous and heterogeneous systems show photocatalyzed hydrogen evolution, the data is summarized in Table 4.

Table 4. Hydrogen production with complex 1 and different catalyst under $445 \mathrm{~nm}$ irradiation.

\begin{tabular}{cccccc}
\hline Catalyst & $\begin{array}{c}\mathrm{TOF}_{\max } \\
\text { mmol }_{H_{2} \cdot} \cdot \text { mol }_{P s} \cdot \text { min }^{-1}\end{array}$ & $\begin{array}{c}\mathrm{TOF}_{\max } \\
\text { mol }_{H_{2} \cdot} \cdot \text { mol }_{P s} \cdot h^{-1}\end{array}$ & $\begin{array}{c}\mathrm{n}_{\mathrm{H} 2}{ }^{\mathrm{a}} \\
\mu m o l\end{array}$ & $\mathrm{TON}^{\mathrm{a}}$ & $\begin{array}{c}\text { Induction } \\
\text { period } h\end{array}$ \\
\hline $\mathrm{K}_{2}\left[\mathrm{PtCl}_{4}\right](50 \mu \mathrm{M})^{\mathrm{b}}$ & 56 & 3.36 & 60 & 116 & $<0.1$ \\
{$\left[\mathrm{Co}(\mathrm{dmgH})\left(\mathrm{dmgH}_{2}\right) \mathrm{Cl}_{2}\right]$} & 53 & 3.18 & 63 & 122 & 1.9 \\
$(1 \mathrm{mM})^{\mathrm{c}}$ & 54 & 3.24 & 62 & 119 & 0.8
\end{tabular}




$\begin{array}{cccccc}(0.5 \mathrm{mM})^{\mathrm{d}} & & & & & \\ {\left[\mathrm{Co}(\mathrm{dmgH})\left(\mathrm{dmgH} \mathrm{H}_{2}\right) \mathrm{Cl}_{2}\right]} & 51 & 3.06 & 395^{\mathrm{e}} & 764^{\mathrm{e}} & 3.4 \\ (1 \mathrm{mM})^{\mathrm{c}, \mathrm{e}} & 57 & 3.42 & 69 & 134 & 0.2\end{array}$

All values are average from multiple runs with $0.1 \mathrm{mM}$ complex 1 in DMF with $1 \mathrm{M}$ triethanolamine as sacrificial donor and $0.1 \mathrm{M}$ tetrafluoroboric acid as proton source; ${ }^{\mathrm{a}}$ Amount of $\mathrm{H}_{2}$ evolved after $44 \mathrm{~h}$ unless stated otherwise $;{ }^{\mathrm{b}}$ Used as precursor for colloidal $\mathrm{Pt} ;{ }^{\mathrm{c}} 6 \mathrm{mM}$ of free $\mathrm{dmgH}_{2}$ ligand added ; ${ }^{\mathrm{d}} 3 \mathrm{mM}$ of free $\mathrm{dmgH}_{2}$ ligand added ; Experiment was conducted for $296 \mathrm{~h}$.

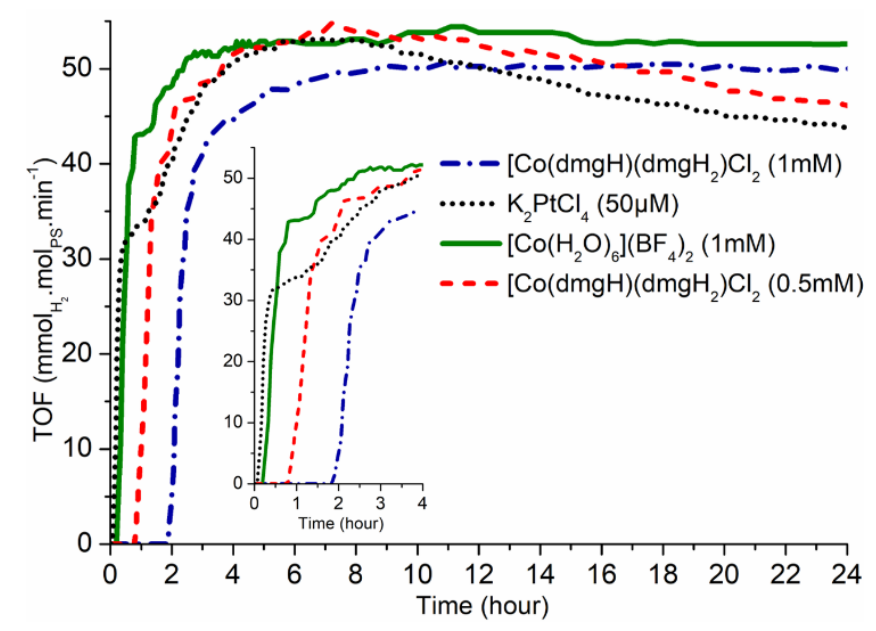

Figure 5. Comparison of the hydrogen evolution performances of complex 1 under blue light irradiation with different catalysts. Insert: First few hours showing the induction period if Co(III) is used as catalyst.

When using the Pt-catalyst, no induction period is observed while the hydrogen production with $\left[\mathrm{Co}^{\mathrm{III}}(\mathrm{dmgH})\left(\mathrm{dmgH}_{2}\right) \mathrm{Cl}_{2}\right]$ only starts after an induction period of several hours. The absence of induction with $\mathrm{Pt}$ is expected since no intermediate species needs to accumulate. However, if one considers the mechanism of catalysis with cobaloxime proposed by Razavet et $a l^{29}$, it appears that the initial Co(III) complex has to be reduced to Co(I), which is assumed to be the active species forming an hydride complex. First, Co(II), which forms as intermediate in the initial reduction step, needs to accumulate before the active species, $\mathrm{Co}(\mathrm{I})$, is finally formed because otherwise any $\mathrm{Co}(\mathrm{I})$ formed in the presence of $\mathrm{Co}$ (III) species could be subject to comproportionation reactions. This hypothesis is confirmed by the following results. When half of the amount of Co(III) catalyst is used, the induction period is halved without affecting the initial rate of activity. Furthermore, when using Co(II), such as $\left[\mathrm{Co}\left(\mathrm{H}_{2} \mathrm{O}\right)_{6}\right]\left(\mathrm{BF}_{4}\right)_{2}$, almost no induction is observed, while a similar rate of activity compared to the previous experiment is again measured. In this case, the observed induction period can be attributed to a partial oxidation of the cobalt during the preparation of the solution in air. Since using different catalysts leads to the maximum TOF of all catalysts to be similar within the experimental error $( \pm 10 \%)$, around $50 \mathrm{mmol}_{\mathrm{H} 2} \cdot \mathrm{mol}_{\mathrm{PS}} \cdot \mathrm{min}^{-1}$, we believe reductive 
quenching by triethanolamine to be the limiting step, which would be coherent with the modest photophysical properties of our photosensitizer.

In general, the Co-containing system showed a better photocatalytic stability than the Ptcontaining ones as the TOF remains almost constant with the Co species, while it decays rapidly with $\mathrm{Pt}$, with a decrease of $20 \%$ in $44 \mathrm{~h}$. Similar photocatalytic instability is only observed when a lower concentration $(0.5 \mathrm{mM})$ of Co catalyst is used, presumably due to the concentration mismatch between photosensitizer and electrocatalyst leading to photodecomposition of the photodegradation of the system. The photocatalytic stability of the system with $1 \mathrm{mM}\left[\mathrm{Co}(\mathrm{dmgH})\left(\mathrm{dmgH}_{2}\right) \mathrm{Cl}_{2}\right]$ as catalyst is further explored and, as shown in Figure 6 , the activity is sustained for at least 12 days, with the TOF decaying slowly from 50 to $40 \mathrm{mmol}_{\mathrm{H} 2} \cdot \mathrm{mol}_{\mathrm{PS}} \cdot \mathrm{min}^{-1}$ after 300 hours.

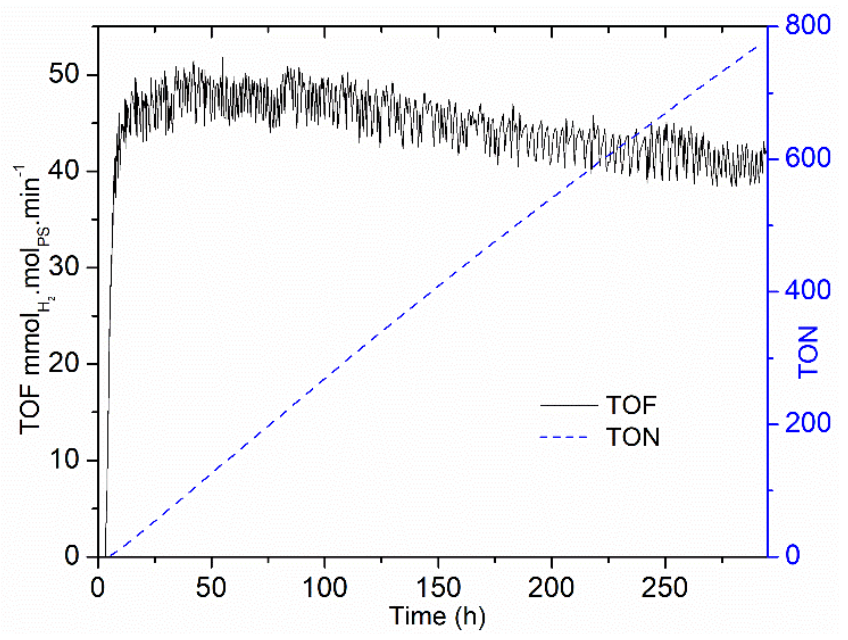

Figure 6. Long term hydrogen evolution using complex 1 under blue light irradiation with $\left[\mathrm{Co}(\mathrm{dmgH})\left(\mathrm{dmgH}_{2}\right) \mathrm{Cl}_{2}\right](1 \mathrm{mM})$ as catalyst.

The observed TOF of complex 1 with the different catalysts is low compared to systems based on $\left[\mathrm{Ru}(\mathrm{bpy})_{3}\right]^{2+}$ or its derivatives reaching thousands of $\mathrm{mmol}_{\mathrm{H} 2} \cdot \mathrm{mol}_{\mathrm{PS}} \cdot \mathrm{min}^{-1}$ but the large increase in stability allows for similar TON as $\left[\mathrm{Ru}(\mathrm{bpy})_{3}\right]^{2+}$ based systems often become inactive within hours. ${ }^{30}$

\section{Conclusion}


A novel heteroleptic $\mathrm{Ru}(\mathrm{II})$ bis terpyridine complex, $\left[\mathrm{Ru}(\text { Tolyltpy)(Bipytpy) }]^{2+}\right.$, is obtained following established synthetic procedures for this type of compound. The photophysical properties of complex $\mathbf{1}$ are improved compared to the related homoleptic complex $\left[\mathrm{Ru}(\text { Tolyltpy })_{2}\right]^{2+}$ with a longer excited-state lifetime and a higher quantum yield, but yet remains humble compared to corresponding bipyridine complexes. The designed donoracceptor structure leads to the expected directional electron transfer towards the more electron-accepting Bipytpy ligand, which possesses pendant pyridine arms preparing complex 1 to interact with a catalyst. The potential of our design is confirmed by photocatalytic hydrogen evolution experiments, in which complex $\mathbf{1}$ appears to be a suitable photosensitizer with both molecular cobalt and colloidal platinum catalysts. The homogeneous system exhibits sustained hydrogen evolution over 12 days albeit with modest activity. This study is the first example of Ru bis terpyridine complex capable of driving a photocatalytic reaction and we expect a renewal of interest for the use of this type of complexes in photocatalytic processes. We are currently exploring other donor-acceptor designs that would lead to enhanced photophysical properties in order to increase the activity while maintaining the stability presented by complex $\mathbf{1}$.

\section{Associated content}

Additional information regarding the instrumentation, electrochemical, crystallographic and theoretical studies as well as hydrogen evolution set-up details and attributed NMR spectra are available in the supplementary materials (PDF). The structure is deposited into the CCDC under the following reference: 1872343.

\section{Corresponding author}

Dirk G. Kurth dirk.kurth@matsyn.uni-wuerzburg.de

Garry S. Hanan garry.hanan@umontreal.ca

\section{Acknowledgments}

G.S.H. thanks the Natural Sciences and Engineering Research Council of Canada for financial support. T.A. and E.R. thanks the Faculté des Arts et Sciences at Université de Montreal for their Marguerite-Jacques-Lemay scholarships. E.R. thanks Mitacs Globalink - Sorbonne 
Université for a research award. This research was enabled in part by support provided by Compute Canada. Financial support by the BayFor is appreciated by M.R. and D.G.K.

\section{References}

1. Kirch, M.; Lehn, J.-M.; Sauvage, J.-P., Hydrogen Generation by Visible Light Irradiation of Aqueous Solutions of Metal Complexes. An approach to the photochemical conversion and storage of solar energy. Helvetica Chimica Acta 1979, 62 (4), 1345-1384.

2. Durham, B.; Caspar, J. V.; Nagle, J. K.; Meyer, T. J., Photochemistry of tris(2,2'bipyridine)ruthenium(2+) ion. Journal of the American Chemical Society 1982, 104 (18), 4803-4810.

3. Berardi, S.; Drouet, S.; Francas, L.; Gimbert-Surinach, C.; Guttentag, M.; Richmond, C.; Stoll, T.; Llobet, A., Molecular artificial photosynthesis. Chemical Society Review 2014, 43 (22), 750119.

4. Fihri, A.; Artero, V.; Pereira, A.; Fontecave, M., Efficient H2-producing photocatalytic systems based on cyclometalated iridium- and tricarbonylrhenium-diimine photosensitizers and cobaloxime catalysts. Dalton Transactions 2008, (41), 5567-9.

5. Rousset, E.; Chartrand, D.; Ciofini, I.; Marvaud, V.; Hanan, G. S., Red-light-driven photocatalytic hydrogen evolution using a ruthenium quaterpyridine complex. Chemical Communications 2015, 51 (45), 9261-9264.

6. Lentz, C.; Schott, O.; Auvray, T.; Hanan, G.; Elias, B., Photocatalytic Hydrogen Production Using a Red-Absorbing Ir(III)-Co(III) Dyad. Inorg Chem 2017, 56 (18), 10875-10881.

7. Rousset, E.; Ciofini, I.; Marvaud, V.; Hanan, G. S., Facile One-Pot Synthesis of Ruthenium(II) Quaterpyridine-Based Photosensitizers for Photocatalyzed Hydrogen Production. Inorg Chem 2017, 56 (16), 9515-9524.

8. Mulfort, K. L.; Tiede, D. M., Supramolecular Cobaloxime Assemblies for H2 Photocatalysis: An Initial Solution State Structure-Function Analysis. The Journal of Physical Chemistry B 2010, 114 (45), 14572-14581.

9. $\quad$ Collin, J. P.; Guillerez, S.; Sauvage, J. P.; Barigelletti, F.; Flamigni, L.; De Cola, L.; Balzani, V., Photoinduced charge separation in dyads and triads containing a ruthenium(II)- or osmium(II)-bisterpyridine photosensitizer covalently linked to electron donor and acceptor groups. Coordination Chemistry Reviews 1991, 111, 291-296.

10. Maestri, M.; Armaroli, N.; Balzani, V.; Constable, E. C.; Thompson, A. M. W. C., Complexes of the Ruthenium(II)-2,2':6',2"-terpyridine Family. Effect of Electron-Accepting and -Donating Substituents on the Photophysical and Electrochemical Properties. Inorganic Chemistry 1995, 34 (10), 2759-2767.

11. Polson, M. I.; Medlycott, E. A.; Hanan, G. S.; Mikelsons, L.; Taylor, N. J.; Watanabe, M.; Tanaka, Y.; Loiseau, F.; Passalacqua, R.; Campagna, S., Ruthenium complexes of easily accessible tridentate ligands based on the 2-aryl-4,6-bis(2-pyridyl)-s-triazine motif: absorption spectra, luminescence properties, and redox behavior. Chemistry - a European Journal 2004, 10 (15), 3640-8.

12. Schwarz, G.; Haßlauer, I.; Kurth, D. G., From terpyridine-based assemblies to metallosupramolecular polyelectrolytes (MEPEs). Advances in Colloid and Interface Science 2014, 207, 107120.

13. Kurth, D. G.; Higuchi, M., Transition metal ions: weak links for strong polymers. Soft Matter 2006, 2, 915-927.

14. Chakraborty, S.; Newkome, G. R., Terpyridine-based metallosupramolecular constructs: tailored monomers to precise 2D-motifs and 3D-metallocages. Chemical Society Reviews 2018, 47 (11), 3991-4016.

15. Pai, S.; Schott, M.; Niklaus, L.; Posset, U.; Kurth, D. G., A study of the effect of pyridine linkers on the viscosity and electrochromic properties of metallo-supramolecular coordination polymers. Journal of Materials Chemistry C 2018, 6 (13), 3310-3321. 
16. Pal, P.; Mukherjee, S.; Maity, D.; Baitalik, S., Synthesis, Photophysics, and Switchable Luminescence Properties of a New Class of Ruthenium(II)-Terpyridine Complexes Containing Photoisomerizable Styrylbenzene Units. Acs Omega 2018, 3 (10), 14526-14537.

17. Wild, A.; Winter, A.; Schlutter, F.; Schubert, U. S., Advances in the field of pi-conjugated 2,2 ':6 ',2 "-terpyridines. Chemical Society Reviews 2011, 40 (3), 1459-1511.

18. Breivogel, A.; Meister, M.; Forster, C.; Laquai, F.; Heinze, K., Excited state tuning of bis(tridentate) ruthenium(II) polypyridine chromophores by push-pull effects and bite angle optimization: a comprehensive experimental and theoretical study. Chemistry - a European Journal 2013, 19 (41), 13745-60.

19. Pal, A. K.; Hanan, G. S., Design, synthesis and excited-state properties of mononuclear Ru(II) complexes of tridentate heterocyclic ligands. Chemical Society Review 2014, 43 (17), 6184-97.

20. Wang, J.; Hanan, G. S., A Facile Route to Sterically Hindered and Non-Hindered 4'-Aryl2,2':6',2'-Terpyridines. Synlett 2005, (08), 1251-1254.

21. Citterio, A.; Arnoldi, A.; Macri, C., Nucleophilic character of acyl radicals. Homolytic acetylation of 4,4'-bipyridine. La chimica e l'industria (Milan) 1978, (60), 14-15.

22. Dehaudt, J.; Husson, J.; Guyard, L., A more efficient synthesis of 4,4',4'-tricarboxy-2,2':6',2'terpyridine. Green Chemistry 2011, 13 (12).

23. Fallahpour, R.-A.; Neuburger, M.; Zehnder, M., Homoleptic and heteroleptic iron(II) and ruthenium(II) complexes of novel 4'-nitro-2,2':6',2"-terpyridines and 4'-amino-2,2':6',2"-terpyridines. New Journal of Chemistry 1999, 23 (1), 53-61.

24. Iranmanesh, H.; Arachchige, K. S. A.; Donald, W. A.; Kyriacou, N.; Shen, C.; Price, J. R.; Beves, J. E., Rage Against Conformity: Ruthenium Bisterpyridine Complexes Respond to Crystal Engineering Instructions with Whelming Results. Australian Journal of Chemistry 2017, 70 (5), 529537.

25. Demas, J. N.; Crosby, G. A., Measurement of photoluminescence quantum yields Journal of Physical Chemistry 1971, 75 (8), 991-1024.

26. Spettel, K. E.; Damrauer, N. H., Synthesis, Electrochemical Characterization, and Photophysical Studies of Structurally Tuned Aryl-Substituted Terpyridyl Ruthenium(II) Complexes. The Journal of Physical Chemistry A 2014, 118 (45), 10649-10662.

27. Bernhard, S.; Goldsmith, J. I.; Takada, K.; Abruna, H. D., Iron(II) and copper(I) coordination polymers: Electrochromic materials with and without chiroptical properties. Inorganic Chemistry 2003, 42 (14), 4389-4393.

28. Fihri, A.; Artero, V.; Razavet, M.; Baffert, C.; Leibl, W.; Fontecave, M., Cobaloxime-based photocatalytic devices for hydrogen production. Angewandte Chemie-International Edition 2008, 47 (3), 564-567.

29. Razavet, M.; Artero, V.; Fontecave, M., Proton Electroreduction Catalyzed by Cobaloximes: Functional Models for Hydrogenases. Inorganic Chemistry 2005, 44 (13), 4786-4795.

30. Hogue, R. W.; Schott, O.; Hanan, G. S.; Brooker, S., A Smorgasbord of 17 Cobalt Complexes Active for Photocatalytic Hydrogen Evolution. Chemistry - a European Journal 2018, 24 (39), 98209832. 